\title{
Olivier LANDRON, Le catholicisme vert. Histoire des relations entre l'Église et la nature au $\mathrm{Xx}^{\mathrm{e}}$ siècle
}

Paris, Éditions du Cerf, coll. «Histoire», 2008, 527 p.

Luis Martínez Andrade

\section{OpenEdition}

1 Journals

\section{Édition électronique}

URL : http://journals.openedition.org/assr/21595

DOI : $10.4000 /$ assr.21595

ISSN : $1777-5825$

Éditeur

Éditions de l'EHESS

\section{Édition imprimée}

Date de publication : 31 décembre 2009

Pagination : 75-342

ISBN : 978-2-7132-2218-4

ISSN : 0335-5985

Référence électronique

Luis Martínez Andrade, "Olivier LANDron, Le catholicisme vert. Histoire des relations entre l'Église et la nature au xx $\mathrm{e}^{\mathrm{e}}$ siècle », Archives de sciences sociales des religions [En ligne], 148 | octobre-décembre 2009, document 148-75, mis en ligne le 27 janvier 2010, consulté le 21 septembre 2020. URL : http:// journals.openedition.org/assr/21595; DOI : https://doi.org/10.4000/assr.21595

Ce document a été généré automatiquement le 21 septembre 2020.

(c) Archives de sciences sociales des religions 


\title{
Olivier LANDRON, Le catholicisme vert. Histoire des relations entre l'Église et la nature au $\mathrm{Xx}^{\mathrm{e}}$ siècle
}

Paris, Éditions du Cerf, coll. «Histoire», 2008, 527 p.

\author{
Luis Martínez Andrade
}

\section{RÉFÉRENCE}

Olivier LANDRON, Le catholicisme vert. Histoire des relations entre l'Église et la nature au xx siècle, Paris, Éditions du Cerf, coll. «Histoire», 2008, 527 p.

1 L'indéniable crise environnementale touche tous les aspects, sociaux, politiques et religieux. Depuis les années soixante-dix, l'intérêt pour les questions écologiques a augmenté; des sociologues, des théologiens, des historiens, parmi d'autres, essaient d'interpréter et de proposer des lectures qui peuvent aider à réparer le chaos actuel. Pour sa part, Olivier Landron, enseignant à l'Université Catholique de l'Ouest, présente, dans son dernier ouvrage, les rapports entre l'Église et la nature. Selon lui, les historiens du catholicisme contemporain n'ont pas abordé suffisamment ces rapports pour deux raisons: d'une part, les relations entre Dieu et l'homme ont été privilégiés, d'autre part, la méfiance à l'égard du panthéisme.

2 La première partie du texte, "Nature et Réflexion», est un recueil très vaste des théologiens, philosophes et penseurs qui ont abordé le rapport entre la nature et la religion. D'après O.Landron, ce lien a été peu travaillé par les historiens du catholicisme contemporain. À partir des débats suscités par les conciles de Vatican I (1869-1870) et de Vatican II (1962-1965), on assiste à une recomposition de la «théologie de la création» et de ses différents courants. Dans l'hexagone, selon O.Landron, la «théologie de la nature» a été fortement marquée par le thomisme qui a conditionné le peu d'intérêt pour les relations entre le Créateur et l'univers (p.16). Néanmoins, l'œuvre du 
jésuite Paul Beauchamp est significative dans le cadre du renouvellement de la pensée chrétienne liée à la nature et aux sciences humaines.

3 À partir des années quatre-vingts du $\mathrm{xx}^{\mathrm{e}}$ siècle, émerge une pléiade de théologiens qui, petit à petit, centrent leur réflexion sur la nature. C'est le cas de Pierre Ganne, René Coste, Jean-Michel Maldamé, Jacques Arnaould, Francois Euvé, entre autres. L'influence de la théologie, surtout allemande et belge, est bien analysée par l'auteur, tout comme son impact sur la liturgie cosmique. Par ailleurs, la figure de Pierre Teilhard de Chardin prend une place importante dans la pensée contemporaine car ses apports en matière de théologie (christogenèse), philosophie (holisme) et science (paléontologie) sont majeurs. À ce propos, le concept de «noosphère» sera repris par le théologien brésilien Leonardo Boff qui, selon la théologie de la libération, se livrera à une critique antihégémonique, autrement dit une remise en question du système capitaliste.

L'«écologie profonde» et le mouvement New Age sont abordés afin de montrer la limite de la pensée chrétienne à propos de la nature. En ce sens, l'auteur propose une esquisse des éléments les plus significatifs de la deep ecology: refus de l'anthropocentrisme, la nature comme sujet de droit, l'hypothèse Gaïa, la critique du cogito dé-corporalisé, le rôle de l'écosophie, etc.

Dans la deuxième partie, «Nature et Contemplation», l'auteur présente quelques mouvements érémitiques et artistiques où l'aspect écologique a eu une importance remarquable. Il y a une différence substantielle au plan politico-religieux entre les anachorètes et les néo-ruraux, mais l'image du désert est fondamentale pour les deux: c'est cette image qui sera transcendante dans les évolutions de Charles de Foucauld, Ernest Psichari et Eric-Emmanuel Schmitt.

6 O. Landron consacre deux chapitres (III et IV) à l'étude de la nature et du religieux dans le domaine de l'art en France. Alors que la tapisserie, la peinture, la musique, le cinéma et la littérature sont des aspects abordés jusque-là, l'auteur remarque la présence de la Genèse biblique, du jardin d'Eden, des psaumes, de la Création, du mythe adamique, de la Terre - en tant que lieu de mémoire - dans l'imaginaire discursif des artistes français.

7 L'auteur observe la redécouverte, durant les années quatre-vingts, de Hildegarde de Bingen et de François d'Assise. À propos de la première qui plaçait «l'homme au centre du monde» (p.164), O. Landron observe qu'elle concevait l'homme en relation étroite avec la nature. Quant au second, François d'Assise et son Cantique des créatures, il sera réétudié par Martial de Salviac et Amédée. À ce sujet, ajoutons que Jean-Paul II luimême l'a désigné comme «le patron de l'écologie» en 1979.

8 Les divergences entre la spiritualité franciscaine et l'écologie profonde sont mises en perspective: la première n'accepte pas l'existence et l'immortalité de l'âme chez les animaux tandis que la seconde considère, d'après une position panthéiste, la nature comme divinité. En ce sens, les réflexions de Gérard Guitton clarifient ce débat.

9 La troisième partie, «Nature et Animation» évoque la manière dont les groupes confessionnels développent des structures et des organisations liées à la question socioécologique. C'est particulièrement le cas des colonies de vacances, du scoutisme et des pèlerinages. L'auteur examine la relation entre la naissance d'une société du loisir et la dynamique téléologique des institutions ecclésiastiques dans le processus d'évangélisation. Parmi les associations qu'il a étudiées, celle des «Compagnons de saint 
François», fondée en 1927, est assez représentative de la revendication du pèlerinage et de l'attitude de rejet du monde industriel et mercantile.

Le scoutisme fut le premier mouvement de jeunesse qui a inclus la nature dans ses principes et sa législation (p.211). Son fondateur, le londonien Robert Baden-Powell avait considéré l'urgence de réformer la société en décadence, et pensait, en accord avec l'esprit de l'Angleterre victorienne, que la morale, la discipline et le respect de l'autorité devaient être des impératifs sociaux. C'est dans ce but qu'il présenta un projet pédagogique dont l'objectif était de corriger l'attitude des enfants et des adolescents. L'action de prêtres comme Jacques Sevin et Jean Rimaud jouera un rôle majeur dans le développement du scoutisme en France au $\mathrm{xx}^{\mathrm{e}}$ siècle.

11 Un aspect intéressant à remarquer est la relation entre politique et religion. À ce sujet, O. Landron évoque la lutte des paysans du Larzac (1971-1981) et le soutien moral et politique de quelques membres de l'Église, comme le père Pierre Bonnefous qui était également influencé par la figure de Lanza del Vasto. La défense de la terre par le biais de la non-violence est une stratégie qui s'opposera au projet de centrale nucléaire à Plogoff (p.328).

«Nature et protection», dernière partie du texte, est consacrée au rapport entre les communautés catholiques et la protection environnementale. À ce sujet, l'auteur examine le rôle des Frères missionnaires des campagnes, le mouvement Pax Christi, le Comité catholique contre la faim dans le monde, la Mission de la mer et l'Action catholique rurale dans le processus d'engagement écologique.

13 O. Landron soutient que, dans l'institution ecclésiale, la protection de la nature sera prise en compte sous le pape Paul VI, lequel, à la Conférence de Stockholm (1972) évoque le lien indéniable entre l'homme et son environnement (p.339). Cependant, c'est avec Jean-Paul II que l'Église catholique se montrera plus concernée par les questions environnementales: rassemblement de Bâle (1989), rencontre de Séoul (1990), Conférence de Rio (1992).

14 Dans la démarche du mouvement altermondialiste, la préoccupation pour l'environnement a été un axe important. Ainsi, il faut remarquer la figure de Chico Whitaker, secrétaire de la commission brésilienne «Justice et paix» qui a fondé le Forum Social Mondial de Porto Alegre. En France, Rémi Mangeart, membre des Frères missionnaires du Moulin de l'Oulme, a été un protagoniste des luttes contre les organismes génétiquement modifiés. Parmi les actions écologistes menées par des individus et groupes confessionnels, on peut citer la pratique du commerce équitable (Frans Van der Hoff), le développement durable (Muhammad Yunnus), la mission de la mer (Mikel Epalza), la méfiance vis-à-vis du nucléaire (Jacques Belliveaud), l'agriculture biologique (Lemaire-Boucher-Racineux) et la défense des animaux (Yves Ellul).

Prenant appui sur une vaste bibliographie, l'ouvrage établit, de façon élargie, un tableau sociohistorique de la démarche qui a suivi la prise en compte du phénomène de l'écologie au sein du catholicisme français au $x^{e}$ siècle. À travers différents domaines, de la littérature à la théologie en passant par la politique, entre autres, l'auteur aborde les implications, les rapports et les limites des attitudes de l'Église vis-à-vis de la nature. 